\title{
To proliferate or to die: role of Id3 in cell cycle progression and survival of neural crest progenitors
}

\author{
Yun Kee and Marianne Bronner-Fraser ${ }^{1}$ \\ Division of Biology, California Institute of Technology, Pasadena, California 91125, USA
}

\begin{abstract}
The neural crest is a unique population of mitotically active, multipotent progenitors that arise at the vertebrate neural plate border. Here, we show that the helix-loop-helix transcriptional regulator Id3 has a novel role in cell cycle progression and survival of neural crest progenitors in Xenopus. Id3 is localized at the neural plate border during gastrulation and neurulation, overlapping the domain of neural crest induction. Morpholino oligonucleotide-mediated depletion of Id3 results in the absence of neural crest precursors and a resultant loss of neural crest derivatives. This appears to be mediated by cell cycle inhibition followed by cell death of the neural crest progenitor pool, rather than a cell fate switch. Conversely, overexpression of Id3 increases cell proliferation and results in expansion of the neural crest domain. Our data suggest that Id3 functions by a novel mechanism, independent of cell fate determination, to mediate the decision of neural crest precursors to proliferate or die.
\end{abstract}

[Keywords: Xenopus; Id3; neural crest; cell cycle; survival]

Received September 1, 2004; revised version accepted January 19, 2005.

The neural crest is an embryonic cell population that originates from the lateral edges of the neural plate during nervous system formation. As the neural plate folds and transforms into the neural tube, neural crest cells emigrate from the forming central nervous system, proliferate extensively, and migrate to numerous destinations. They then differentiate into diverse derivatives ranging from neurons and glia of the peripheral nervous system to cartilage of the face, smooth muscle, and melanocytes (Groves and Bronner-Fraser 1999; LaBonne and BronnerFraser 1999; Le Douarin and Kalcheim 1999; Knecht and Bronner-Fraser 2002; Gammill and Bronner-Fraser 2003). Although many studies have focused on induction of the neural crest precursor pool, the molecular signals and mechanisms underlying early events such as cell proliferation and survival of the neural crest are not yet understood. In Xenopus, neural crest induction requires at least two signals including Wnt/FGF signaling and inhibition of BMP signaling (Saint-Jeannet et al. 1997; LaBonne and Bronner-Fraser 1998; Marchant et al. 1998). Although several transcription factors such as Snail (Essex et al. 1993), Slug (LaBonne and Bronner-Fraser 2000; Mayor et al. 2000), Sox9 (Spokony et al. 2002), Sox10 (Aoki et al. 2003; Honore et al. 2003), AP2 $\alpha$ (Luo

${ }^{1}$ Corresponding author.

E-MAIL mbronner@caltech.edu; FAX (626) 395-7717.

Article and publication are at http://www.genesdev.org/cgi/doi/10.1101/ gad. 1257405 et al. 2003), c-Myc (Bellmeyer et al. 2003), and Msx1 (Tribulo et al. 2003) have been identified in Xenopus as transcriptional regulators of neural crest specificaion, the molecular understanding of how these cells arise and the molecular network linking these regulaors of neural crest formation still remains to be established.

Members of the Id (inhibitor of DNA binding or inhibitor of differentiation) gene family possess a helixloop-helix domain that is required for dimerization and negatively influences the ability of tissue-specific basic helix-loop-helix (bHLH) transcription factors to bind to DNA (Norton et al. 1998; Norton 2000; Yokota 2001; Tzeng 2003). The Drosophila ortholog of Id, extramacrochaetae (emc), antagonizes Daughterless and achaete-scute bHLH proteins involved in sex deterination and neurogenesis, acting as a negative regulator of differentiation (Ellis et al. 1990; Garrell and Modolell 1990). The Id genes have highly overlapping expresion patterns in mice (Evans and O'Brien 1993; Jen et al. 1997; AndresBarquin et al. 2000), making analysis of their loss-offunction phenotype difficult because of functional redundancy. Targeted gene disruption of Id1, Id2, or Id 3 in mice yields mutant animals that develop normally and are viable, with major defects appearing post-natally in the immune system (Lyden et al. 1999). Double knockout mice of Id1 and Id3 survive to adulthood; however, neuroblasts in the brain prematurely differentiate, implicating Id genes as positive regulators of cell cycle control 
of neural precursors (Lyden et al. 1999). These mice also exhibit vascular malformations in the forebrain and defects in the branching and sprouting of blood vessels into the neuroectoderm. Chick Id2 is localized in the cranial neural folds and subsequently in a subpopulation of migrating cranial neural crest cells, and overexpression experiments in the chick suggest that Id 2 may play a role in neural crest development in this species (Martinsen and Bronner-Fraser 1998). However, loss-of-function analysis was not performed due to technical difficulties in the chick.

Id genes have been implicated in the regulation of diverse cellular events such as controlling cell cycle, proliferation, differentiation, or apoptosis of different cell types in several in vitro mammalian cell line models (Tzeng 2003). However, the mechanisms that mediate their effects in developing tissues in vivo are not well understood. Xenopus embryos offer several advantages for functional analysis of genes involved in neural crest development because it is possible to focally inject mRNAs and small interfering constructs into specific tissues for both gain- and loss-of-function studies. Here, we report that Xenopus Id3 is the only Id expressed in newly formed and migrating neural crest; furtherore, morpholino antisense oligonucleotide-mediated knockdown of Id 3 protein causes depletion of neural crest precursors and their derivatives. This loss apparently occurs via cell cycle inhibition followed by cell death of the precursor population rather than via a cell fate switch. Our results demonstrate an essential role of $\mathrm{Id} 3$ in mediating neural crest cell proliferation and cell survival.

\section{Results \\ Id3 is expressed in premigratory and migratory neural crest cells during Xenopus embryogenesis}

Neural crest development requires proper expression of regulatory molecules in neural crest precursor cells at appropriate times. Although the expression patterns of Id2, Id3, and Id4 have previously been examined in Xenopus embryos (Wilson and Mohun 1995; Zhang et al. 1995; Liu and Harland 2003), no Id gene was identified in early neural crest progenitors in Xenopus. Our in situ hybridization revealed that Xenopus Id3, but not other Id genes, was expressed in neural crest progenitors. We then performed a detailed analysis of the expression pattern of $I d 3$ as a function of time from gastrulation through the early stages of neural crest migration. At the beginning of gastrulation, Id3 was expressed broadly throughout the non-neural ectoderm in the animal half of the embryo. As gastrulation proceeded, Id3 expression was down-regulated above the dorsal lip (Fig. 1A). During initial stages of patterning of the prospective neural plate, it was down-regulated in the newly formed neural plate in a pattern emanating from the organizer toward the dorsal and anterior region of the embryos (Fig. 1B). At early neurula stages, the expression was maintained at the neural plate border where neural crest precursors lie, but down-regulated elsewhere (Fig. 1C,D). In addition to the neural folds, prominent expression was noted in two stripes at the mid-hindbrain boundary and hindbrain level (Fig. 1D,E).

To verify that Id3 was, indeed, expressed in the neural crest, we performed double in situ hybridization with
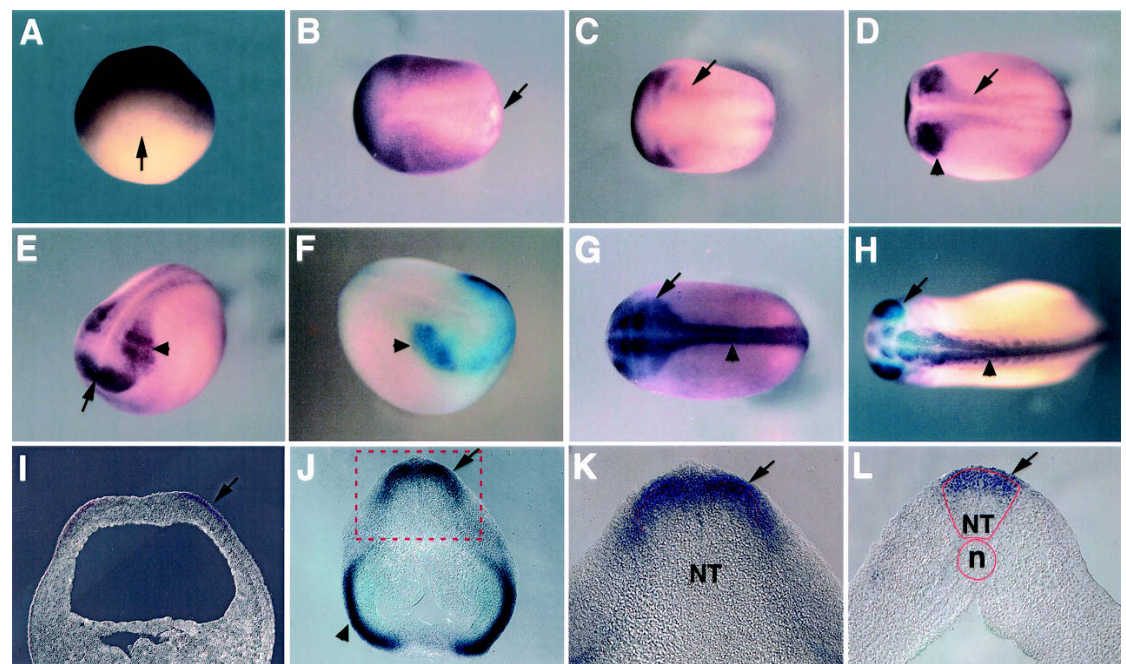

Figure 1. $I d 3$ is expressed in premigratory and migratory neural crest cells. (A) Id3 expression at the gastrula stage (stage 10.5). $I d 3$ expression is seen in the ectoderm of the animal half of the embryo and starts to decrease in the region above the dorsal lip (arrow). $(B-D)$ Dorsal views of embryos at stages 12.5-15 (anterior toward left). Id3 expression is progressively down-regulated through late-gastrula and early-neurula stages and maintained at the neural plate border. Arrows indicate blastopore $(B)$, and neural fold $(C, D) .(D)$ The arrowhead indicates the hindbrain region. (E) Anterior lat eral view of $I d 3$ expression at stage $15 . I d 3$ is clearly expressed in the anterior neural plate (arrow), midbrain and hindbrain regions in two stripes, and at the neural plate border including the premigratory neural crest domain (arrowhead). (F) Double in situ hybridization with Id3 and FoxD3 RNA. The foxD3 expression (purple) overlaps with the Id3 expression (light blue) in the neural crest domain (arrowhead). The Id3-expressing region is slightly larger than the foxD3-expressing neural crest domain. (G) Dorsal view of $I d 3$ expression at stage 21 . Id 3 is expressed in migrating cranial neural crest cells (arrow) and the trunk neural fold region (arrowhead). ( $H$ ) Dorsal view of $I d 3$ expression at stage 23. Id3 is expressed in the dorsal neural tube at cranial and trunk levels (arrowhead) as well as in the optic placode (arrow). (I) Section of an early-neurula-stage embryo showing Id3 expression in the superficial layer (arrow) at the border of neuronal and non-neuronal ectoderm. $(J, K)$ Section of an embryo showing migrating neural crest cells (arrow) coming out of the cranial dorsal neural tube at stage 22. Id3 expression in the dorsal neural tube $(J)$ is magnified in $K$. Id3 is also expressed in the optic placode (arrowhead). (NT) Neural tube. (L) Id3 expression in the trunk dorsal neural tube and neural crest cells (arrow) coming out of the dorsal neural tube as well as in the ectoderm above it. (NT) Neural tube; (n) notochord. 
the early neural crest marker, FoxD3. The expression of $I d 3$ and $f_{0 x D} 3$ overlapped in the premigratory neural crest domain (Fig. 1F), although the $I d 3$ expression domain was slightly broader than the foxD 3 expression domain and may include tissues adjacent to the neural plate border (Fig. 1F). Transverse sections of stage $15 \mathrm{em}$ bryos confirmed that $I d 3$ expression was in the superficial layer of the premigratory neural crest (Fig. 1I). In addition, Id3 was prominent in the anterior neural plate of the embryo, a region corresponding to the future cephalic placodal domain (Fig. 1E).

With the onset of neural crest migration, transient expression of $I d 3$ was noted in streams of migrating neural crest cells emanating from the cranial neural tube (Fig. $1 \mathrm{G}, \mathrm{J}, \mathrm{K})$ as well as in premigratory and migrating trunk neural crest cells (Fig. 1H,L). These results demonstrate that Id 3 is expressed in both cranial and trunk premigratory and early migratory neural crest cells.

\section{Regulation of Id3 gene expression by signaling events during neural crest induction}

The localization of $I d 3$ to the neural crest domain leads to the question of whether the process of neural crest induction specifically regulates $I d 3$ expression in this border domain. In Xenopus, a combination of signaling pathways has been shown to mediate neural crest induction in vivo. These include a neuralizing signal, together with a Wnt and/or FGF-like signal (Mayor et al. 1997; Saint-Jeannet et al. 1997; LaBonne and Bronner-Fraser 1998). Consistent with this, Wnt signaling in combination with BMP antagonists acting as neuralizing factors induce neural crest markers in vitro in naïve ectoderm grown in animal cap culture (LaBonne and Bronner-Fraser 1998).

We took advantage of this ability to recapitulate neural crest induction in vitro to compare the levels of $I d 2$, $I d 3$, and Id4 with the early neural crest marker slug in animal caps injected with the BMP antagonist chordin (Chd) and/or wnt8 (Fig. 2). slug expression was robustly induced only when both Chordin and Wnt signalings were combined, as previously shown (Fig. 2). Of all the Id genes, only Id 3 mRNA was maintained at high level or slightly up-regulated in animal caps under neural crestinducing condition, whereas Id3 expression was downregulated by Chordin or Wnt signal alone. Id4 was upregulated when only Chordin was expressed but downregulated with Wnt8 alone or with combinations of Chordin and Wnt signals. Id2 expression was down-regulated under all conditions. These results show that among the known Xenopus Id genes, only Id3 expression is robustly maintained in response to signaling events of early neural crest induction. This mimics its dynamic in vivo expression pattern during neural as well as neural crest induction at gastrula and neurula stages (Fig. 1A-D).

\section{Id3 is essential for neural crest precursor formation} in Xenopus

To block the function of Id3 in Xenopus neural crest development, we designed a morpholino antisense oligo-

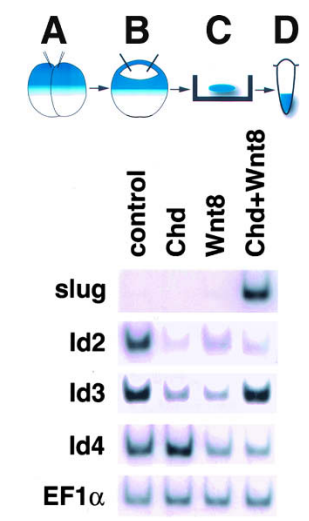

Figure 2. RT-PCR analysis in ectodermal explants of embryos injected with chordin and wnt8 RNA. Animal caps were dissected from the embryos injected with $100 \mathrm{pg}$ of chordin (Chd) and/or 200 pg of wnt8 RNA, cultured until stage 18 and subjected to RT-PCR. Neural crest marker slug expression is induced only in the presence of both chordin and wnt 8 as previously shown. Only Id3 is maintained under the neural crestinducing conditions, while Id4 was maintained or up-regulated under neuralizing condition. EF1 $\alpha$ expression is used as a loading control.

nucleotide (Id3-MO) corresponding to the $5^{\prime}$-upstream sequence of the start codon in Id3 gene (Fig. 3A), as well as a control morpholino oligonucleotide (control-MO) containing seven base pair mismatches spread out along the length of the Id3-MO sequence (Fig. 3A). To verify the specificity of the morpholino oligonucleotides, we first performed an in vitro translation assay. The results show that the Id3 protein synthesis is blocked only in the presence of the Id3-MO, but not by control-MO or morpholino oligos designed against other Id genes (Fig. 3B).

We next examined the in vivo effect of Id3 protein depletion by injecting the morpholino oligos into embryos at the eight-cell stage, specifically targeting the neural crest domain, together with nuclear $\beta$-galactosidase RNA as a lineage tracer to mark the region of injection (Red-Gal, red color; X-Gal, turquoise color). To visualize the effect on early neural crest induction, we performed in situ hybridization for transcription factors such as Slug, Sox10, FoxD3, and Twist (Fig. 3C; data not shown). The control-MO had no effect on neural crest markers on the injected side relative to the uninjected side (Fig. 3C, panel a, $n=45$ ). In contrast, all the neural crest markers were reduced or obliterated from the region injected with Id3-MO (Fig. 3C, panels b-d, $n=40$ 70 for each). This effect was dose-dependent (data not shown), and $5 \mathrm{ng}$ of Id3-MO for each injection produced a consistent and reproducible phenotype. A morpholino oligonucleotide against Id2 (Id2-MO) had no effect on neural crest induction (Fig. 3D). The effect of Id3-MO on neural crest induction was rescued in the presence of chick Id3, an ortholog of Xenopus Id3 containing different nucleotide sequences at the translation initiation site so as not to be subject to the effects of Xenopus Id3-MO (Fig. 3E). In contrast, Xenopus Slug was unable to rescue the Id3-MO phenotype (data not shown). These 
A

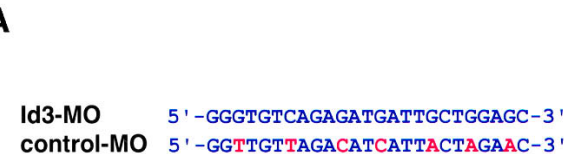

B

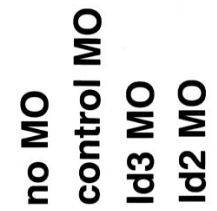

Id3
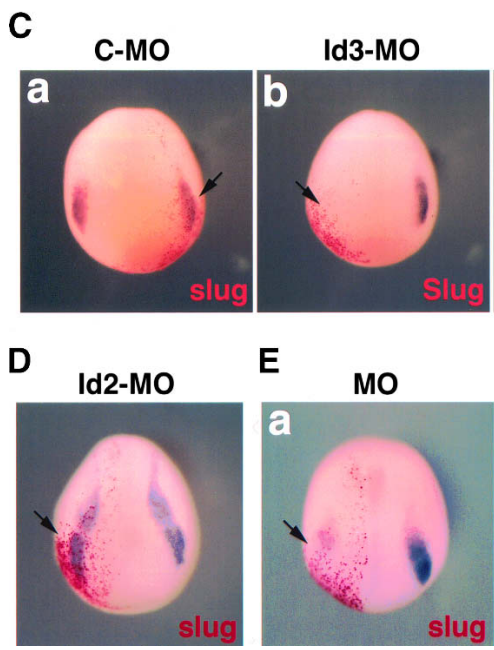

E

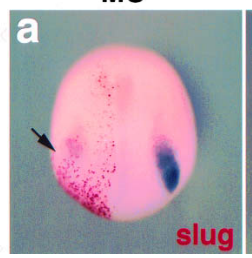

Id3-MO

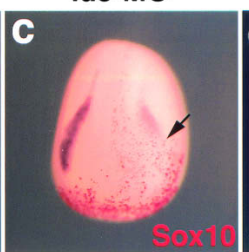

MO+cld3

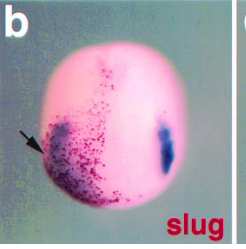

Id3-MO

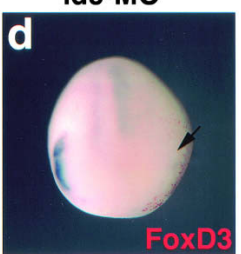

MO+cld3

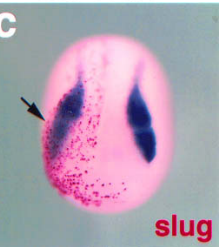

Figure 3. Id 3 depletion leads to a loss of neural crest progenitors. (A) Morpholino antisense oligo sequence (Id3-MO) corresponding to a region $5^{\prime}$ upstream of the Id3 start codon (25 bp; -8 to -32$)$ and its control oligo (control-MO) with seven mismatches (red letters). $(B)$ Id3 protein synthesis was monitored in the absence of oligo (no MO) or in the presence of morpholino oligos (control, Id 3 or Id2 oligo) in an in vitro translation system. Only Id3-MO specifically blocks Id3 protein translation. $(C)$ Neurula-stage embryos injected with control-MO or Id3-MO. (Panel a) slug expression (arrow) is intact on the side injected with control-MO (C-MO, Red-Gal). (Panels $b-d$ ) Embryos injected with Id3-MO show the loss of early neural crest markers (arrows) on the injected side, which is marked by Red-Gal staining: slug (panel $b$ ), sox10 (panel $c$ ), and foxD3 (panel $d$ ). (D) slug expression is not affected by Id2 depletion (arrow). $(E)$ The loss of neural crest progenitors by Id 3 depletion (panel $a$ ) is rescued in the presence of chick Id3 (panels $b, c)$.

results show that Id 3 is required for either the formation or the maintenance of the premigratory neural crest population.

\section{Id3 depletion causes the loss of cranial and trunk neural crest derivatives}

The above results suggest that Id 3 is necessary for early steps in neural crest development, but we cannot rule out the possibility that neural crest development may be temporally delayed in the absence of this protein. To address this issue, we first looked at the long-term effects of Id 3 loss of function on neural crest derivatives by allowing injected embryos to grow to tadpole stages. By this time, several neural crest-derived structures and cell types are morphologically identifiable, including cranial neural crest-derived branchial arch cartilage and trunk neural crest-derived dorsal fins and melanocytes.

By external examination, Id3-MO-injected embryos looked abnormal, with an apparent loss of facial structures on the injected side (Fig. 4A, panels a,b for control$\mathrm{MO}$, panels c,d for Id3-MO). To examine the branchial arch defect in detail, the cartilage was stained with Alcian blue and dissected from the head mesoderm. Normally, the cartilage has a bilaterally symmetric pattern with Meckel's cartilage in the anterior portion, followed by certohyal, basihal, and branchial cartilages from rostral to caudal (Fig. 4B, panel a). When the control-MO was injected into wild-type embryos at the eight-cell stage, the cartilage appeared normal, as shown in the schematic diagram (Fig. 4B, panel b, $n=40,100 \%$ normal). In Id3-MO-injected embryos, however, the cartilages were either entirely depleted or greatly reduced in size on the injected side but normal on the control side, with degrees of depletion varying with site of injection (Fig. 4B, panels c,d, $n=46,46 \%$ externally defective).

Similar to the abnormalities observed in the branchial arches, the dorsal fin appeared to collapse upon itself in morpholino-injected embryos, since one side was nearly missing (Fig. 4C, panel a for control-MO [100\% normal, $n=34]$, panel b for Id3-MO [36\% collapsed fin, $n=45]$ ). The mesenchyme of the dorsal fin is entirely neural crest-derived, suggesting that the fin malformation is likely due to a significant loss of the neural crest population. In contrast, the somite size and morphology on the Id3-MO-injected side of the embryo appeared normal, and anterior-to-posterior patterning was not disturbed (Fig. 4D, panels a,b).

At later tadpole stages, the phenotype of melanocyte development was somewhat variable and difficult to quantitate, since these cells are highly motile, moving superficially under the ectoderm and readily crossing the midline. Therefore, Id3-MO-injected embryos were collected at tailbud stage (stage 31) and hybridized for tyrosinase-related protein-2 (Trp-2) mRNA that is expressed in melanoblasts near the dorsal neural tube at early stages (Aoki et al. 2003). trp-2 expression revealed a large decrease in pigment cell formation on the Id3-MOinjected side (Fig. 4E, panels a,c) relative to the control side (Fig. 4E, panels b,d), demonstrating that melanocyte development was affected in the Id3-depleted embryos.

Some of the neurons and glia of the cranial sensory ganglia originate from cranial neural crest precursors, with the remaining cells derived from ectodermal placodes (Baker and Bronner-Fraser 2001). Sox10 is expressed in migrating cranial neural crest, in cranial ganglia of the peripheral nervous system, and in glia of the central nervous system (Britsch et al. 2001). In Id3-depleted em- 
Figure 4. Id 3 depletion results in a loss of neural crest derivatives. (A) Dorsal (panel $a$ ) and ventral (panel $b$ ) views of an embryo injected with controlMO showing symmetrical head morphology. Dorsal (panel $c$ ) and ventral (panel $d$ ) views of an embryo injected with Id3-MO exhibiting structural loss on the injected side (arrow). The arrowhead indicates the midline. $(B$, panel $a)$ Schematic diagram of cartilages in a stage 45 embryo. The different colors indicate the skeletal elements originate from different streams of migrating cranial neural crest. Meckel's (i), cerathoyal (ii), basihyal (iii), and branchial arch (iv) cartilages are shown here. (Panel $b$ ) Cartilage staining of a control embryo shows the symmetrical structures shown in the diagram. (Panels $c$, d) Whole or partial loss of cartilage on the Id3-MOinjected side. The dotted red line indicates the midline. $(C)$ The dorsal fin of a control-MO-injected embryo is intact (panel $a$ ), but an Id3-MO-injected embryo exhibits a collapsed dorsal fin by depletion of the structure on the injected side (panel $b)$. (D) Anterior and posterior patterning in Id3-MO-injected embryos is normal (panel $b$ ) compared with the control (panel $a$ ). (E) Stage 31 embryo injected with Id3$\mathrm{MO}$ and subjected to in situ hybridization with a trp-2 probe. (Panels $a, b)$ Eyes express trp-2. trp-2positive pigment cells (purple) that are newly synthesized (dorsal neural tube; white arrow) or migrating superficially under the ectoderm (lateral; black arrowhead) are depleted or decreased on the Id3-MOinjected side (panels $a, c$ ), compared with the control

A
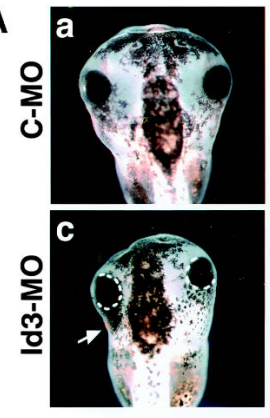

C

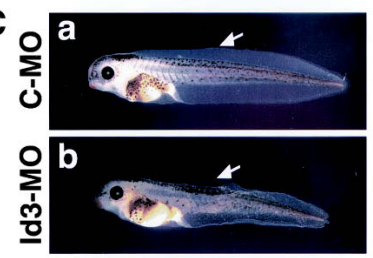

D
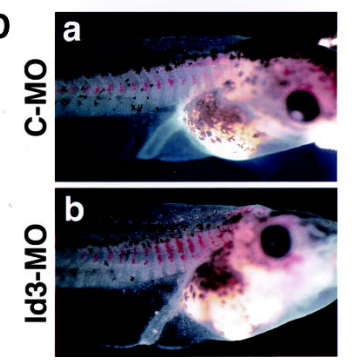
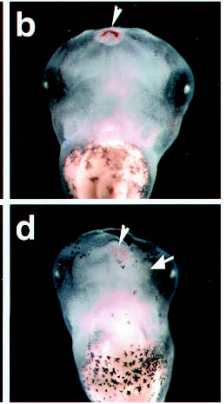

B a

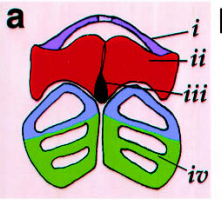

C

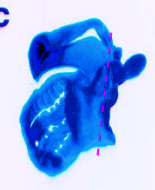

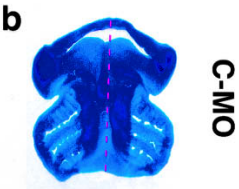

d

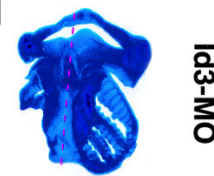

side (panels $b, d)$. (Panels $a, c)$ Red dots (red arrow) are Red-Gal staining indicating Id3-MO-injected cells. $(F)$ sox10 expression is lost in migrating neural crest cells destined to give rise to cranial ganglia (V, VII, IX, and X) on the Id3-MO-injected side that is marked by Red-Gal staining (panel $a$ ), compared with the control side (panel $b$ ).

bryos, sox10 expression was greatly reduced in migrating cranial neural crest cells and in their cranial ganglia on the Id3-MO-injected side (Fig. 4F, panel a), whereas the uninjected side displayed characteristic sox10 expression in distinct streams of migrating neural crest cells contributing to the developing trigeminal ganglia as well as the seventh, ninth, and tenth cranial ganglia (Fig. 4F, panel b). n-tubulin expression in developing cranial sensory neurons was also decreased on the Id3-depleted side (data not shown). This result indicates that $\mathrm{Id} 3$ is required for the normal development of neurons derived from the neural crest and/or neurogenic placodes. This is consistent with our previous observation that the early expression domain of $I d 3$ was slightly broader than the early neural crest domain (shown by slug expression), including the future neurogenic placodal region (Fig. 1F). Taken together, these data suggest that loss of Id3 protein affects a diverse range of neural crest and placodederived cell types, rather than targeting a particular subpopulation.

\section{Id3 is essential for cell cycle progression and survival of neural crest progenitors}

Several mechanisms could account for the loss of neural crest markers and derivatives in Id3-MO-injected embryos. One possibility is that the lack of $\operatorname{Id} 3$ drives neural crest precursors into another lineage, for example, becoming neural at the expense of neural crest. Indeed, this effect on cell fate determination has been shown for several transcription factors involved in neural crest specification, including Slug, FoxD3, Sox9, Sox10, and c-Myc; knock-down or dominant-negative effects of these genes in Xenopus have been shown to expand the neural plate at the expense of the neural crest (LaBonne and Bronner-Fraser 2000; Sasai et al. 2001; Spokony et al. 2002; Bellmeyer et al. 2003; Honore et al. 2003). Alternatively, Id 3 may play a role in promoting proliferation and/or survival of the neural crest precursor pool. In contrast to factors that affect cell fate decisions, loss of this function would be predicted to deplete the neural crest population while leaving other cell populations intact.

To distinguish between these possibilities, we first examined whether there was expansion of neural ectoderm in embryos injected with Id3-MO. Interestingly, the neural plate as revealed by the neural plate marker sox2 was not expanded, but fox $D 3$ expression in premigratory neural crest was decreased or obliterated by Id3-MO injection (Fig. 5A). This demonstrates that the neural crest cells affected by Id 3 depletion were not replaced by expansion of the neural domain, suggesting they did not alter their fate.

If $\mathrm{Id} 3$ regulates proliferation of neural plate border 

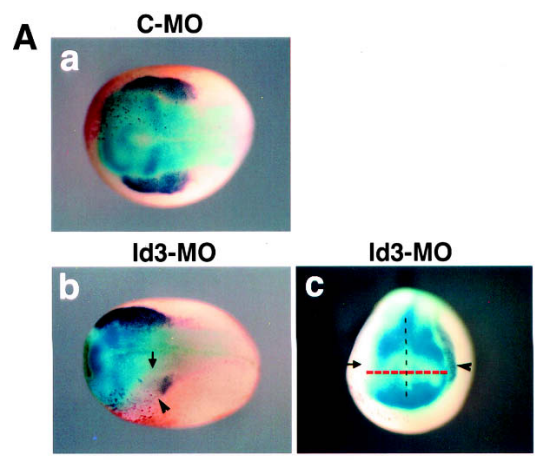

B
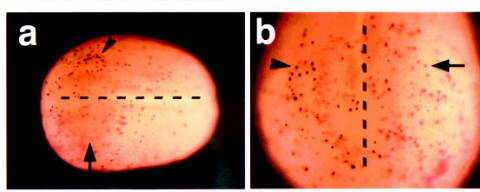

C a
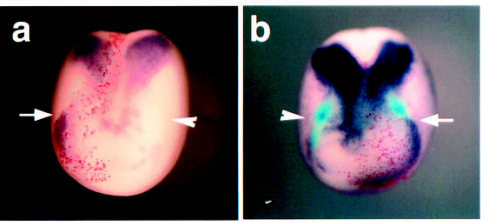

D a
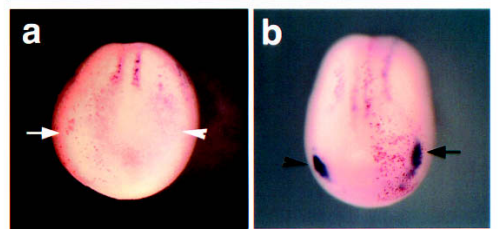

E
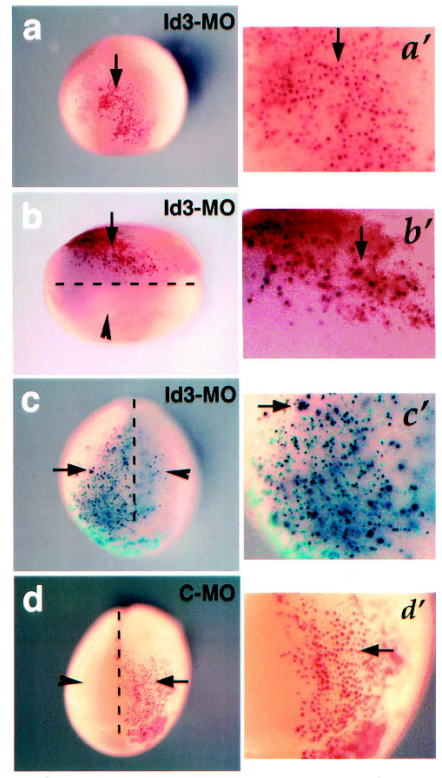

F

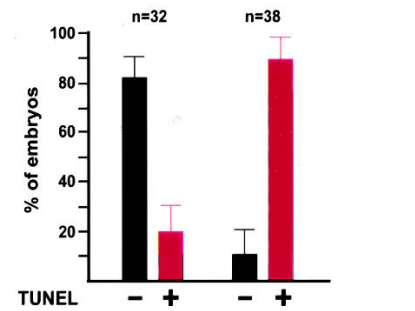

Figure 5. Id3 is required for cell proliferation and survival of neural crest. $(A)$ Neurula-stage embryos injected with morpholino oligos and subjected to double in situ hybridization with FoxD3 and Sox2 RNA probes. (Panel $a$ ) Dorsal view of a control embryo (anterior toward left) shows foxD3 expression (purple) intact on the side injected with control-MO (Red-Gal). (Panels $b, c)$ Dorsal view of an embryo (anterior toward left) injected with Id3-MO and anterior view of another embryo injected with Id3-MO show that the neural crest marker foxD3 (purple, arrowhead) is lost on the injected side (Red-Gal), while the neural plate (border line, arrow) marked by sox2 expression (light blue) is not expanded (red dotted line) and does not replace the neural crest. The black dotted line indicates the midline. $(B)$ Cell proliferation assay measured by immunostaining with antiphosphorylated histone $\mathrm{H} 3$ antibody in an embryo injected with Id3-MO. Dorsal view (panel $a$ ) and magnified anterior view (panel $b$ ) of an embryo show that mitotic cells (black dots at control side, arrowhead) are absent or decreased in the neural crest region injected with Id3-MO (arrow, Red-Gal). (C) Expression of cell cycle inhibitor in the embryos injected with Id3-MO. (Panel a) $p 27^{X i c I}$ (purple, arrow) is ectopically expressed in neural crest progenitors when Id3 is depleted (white arrow). (Panel $b$ ) Double in situ hybridization reveals that foxD3 expression (light blue, arrowhead) in neural crest is replaced by $p 27^{X i c l}$ expression (purple, arrow) at the side injected with Id3-MO (Red-Gal). (D) Differentiation markers in the embryos injected with Id3-MO. n-tubulin (panel $a$ ) and NeuroD (panel $b$ ) are not ectopically expressed in the neural crest at the side injected with Id3-MO at stage 13. (Panel $b$ ) Their expression is slightly increased in trigeminal ganglia at the side injected with Id3-MO (arrow) at stage 14. (E) TUNEL staining in the embryos injected with Id3-MO or control-MO. (Panels $a, a^{\prime}$ ) Id3-MO-injected region (Red-Gal) of a stage 11 embryo is negative (arrow, no black dot) in TUNEL staining. (Panels $b, b^{\prime}$ ) Dorsal view of a stage 14 embryo (anterior toward left) shows significantly increased cell death (black dots, arrow) on the neural crest region injected with Id3-MO (Red-Gal), compared with the uninjected side (arrowhead). (Panels $c, c^{\prime}$ ) Anterior view of a stage 17 embryo also shows elevated cell death (black dots, arrow) on the neural crest region injected with Id3-MO (X-gal staining, turquoise color), compared with the uninjected side (arrowhead). (Panels $\left.d, d^{\prime}\right)$ Anterior view of a stage 16 embryo injected with control-MO shows that cell death doesn't occur in the injected region (Red-Gal, arrow), compared with the uninjected side (arrowhead). The MO-injected region is magnified for each embryo in $a^{\prime}-d^{\prime}$. (F) The graph illustrating the results of TUNEL staining as percentages of TUNEL-negative (black bar) or TUNEL-positive (red bar) embryos out of the embryos injected with control-MO or Id3-MO.

cells, then the loss of neural crest gene expression and, ultimately, neural crest derivatives in Id3-MO-injected embryos may be due to a failure of a small group of precursors to proliferate. To examine this possibility, we examined cell proliferation in the Id3-MO-injected embryos using an antibody against phosphohistone $\mathrm{H} 3$, a marker of cells in mitotic prophase. Interestingly, the results show a profound decrease in the numbers of proliferating cells in a discrete population adjacent to the neural plate on the injected side (Fig. $5 \mathrm{~B}, n=23,91 \%$ ). Based on this result, we examined whether cell cycle control was specifically affected in those cells. p2 $7^{\text {Xic1 }}$ belongs to the Cip/Kip family of CDK (cyclin-dependent kinase) inhibitors that negatively control the cell cycle by binding to and inactivating cyclin-CDK complexes (Su et al. 1995; Sherr and Roberts 1999; Vidwans and Su 2001). We found that the cell cycle inhibitor $p 27^{X i c 1}$ was ectopically expressed in the neural crest progenitors and adjacent cells when Id 3 was depleted (Fig. 5C). This dem- onstrates that Id 3 is required for cell cycle progression of neural crest progenitors.

One possibility is that blocking cell cycle progression may lead to premature differentiation, which could secondarily cause loss of neural crest progenitors. To check this possibility, we examined expression of differentiation markers of neuronal and epidermal cells in the Id3depleted embryos at the time of neural crest formation (Fig. 5D; data not shown). None of these was ectopically expressed in neural crest progenitors, making it unlikely that premature differentiation is the cause of the depletion of neural crest progenitors. At later stages, the expression of neuroD and n-tubulin was slightly increased in trigeminal ganglia but decreased on the lateral sides of neural plate (Fig. 5D; data not shown).

In addition to cell cycle progression, Id3 may play a role in cell survival during neural crest development. The first clue that this may be the case came from embryos injected with Id3-MO, which often showed a sig- 
nificant loss of cells expressing the lineage tracer $\beta$-galactosidase in the injected side at early stages (Fig. 3C,E). A possible explanation for this observation is that depletion of Id3 may cause cell death. To test this possibility, we performed a TUNEL assay to examine whether Id3 protein knock-down led to increased apoptosis in the neural crest population. As TUNEL displays a significant level of variability (Hensey and Gautier 1998), we quantitated the results by counting the numbers of embryos with significantly more positive cells on the injected side compared with the noninjected side. Examination of the Id3-depleted embryos stained by TUNEL revealed that there was, indeed, an increase in the numbers of dying cells on the Id3-depleted side, relative to the control side in the neurula-stage embryos (Fig. 5E [panels $\mathrm{b}, \mathrm{b}^{\prime}, \mathrm{c}, \mathrm{c}^{\prime}$ ], $\mathrm{F}$ [graph], $n=38,89 \%$ positive). Cell death after Id3 depletion was detected at late gastrula to early neurula stages (Fig. 5E, panels $\mathrm{b}, \mathrm{b}^{\prime}, \mathrm{c}, \mathrm{c}^{\prime}$ ) but not at early gastrula stages (Fig. 5E, panels a, $\mathrm{a}^{\prime}$ ). In contrast, embryos injected with control-MO displayed no significant difference between the injected and uninjected sides at all these stages (Fig. 5E [panels d,d'], F [graph], $n=32,81 \%$ negative). Several TUNEL-stained nuclei in Id3-MO-injected embryos appeared larger in size than normal nuclei (Fig. 5E, panels $b^{\prime}, c^{\prime}$ ), suggesting that their mitoses may be blocked. These results suggest that $\mathrm{Id} 3$ is required for both neural crest cell survival and proliferation, rather than affecting cell fate determination as do other transcriptional regulators known to be important for neural crest development in Xenopus.

\section{Id overexpression induces the expansion of neural crest}

As Id3 appears important for neural crest proliferation, enhanced Id expression in the neural crest would be predicted to increase the numbers of neural crest cells. Accordingly, overexpression of Id 3 resulted in a profound expansion of the neural crest population on the injected side (Fig. 6A, panels a,b). This effect was mimicked by other Ids, such as Id4, which are not normally expressed in the early neural crest domain (Fig. 6A, panel c; Liu and Harland 2003). In addition, all chick Id genes had similar effects to that of Xenopus Id3 (Fig. 6A, panels d-f). These results suggest that all Ids may have similar biological effects on neural crest progenitors and that the specific effect of Id3 results from its unique deployment in this cell population at the neural plate border.

Overexpression of Id3 may cause neural crest expansion by reducing cell death and/or by increasing proliferation of neural crest cells. TUNEL assays revealed little cell death in vivo in the neural crest of either normal embryos (Fig. 5E) or after Id3 overexpression (data not shown). Thus, it is unlikely that reduced cell death can account for the observed neural crest expansion /data not shown). In contrast, a BrdU-labeling experiment revealed an increase in the number of cells undergoing division at the neural plate borders injected with Id3 (Fig. 6B), suggesting that Id3 increases proliferation of neural crest cells. We also probed the long-term phenotype of Id3 overexpression by examining the effects on neural crest-derived structures at tadpole stages. Although cranial and trunk structures looked normal overall, younger tadpoles began to produce more melanophores from the dorsal neural tube; transverse sections hybridized with trp-2 RNA revealed that the melanophores came out from the injected side much more frequently than the control side and then migrated bilaterally (Fig. 6C; data not shown). Other structures like neural crest-derived ganglion appeared normal in size, likely due to size regulation compensating for initial increases or decreases in cell number (C. Baker, unpubl.). These data suggest that Id3 promotes cell proliferation of neural crest progenitors but that additional mechanisms may be responsible for the final size of neural crest-derived structures.

\section{Discussion}

Id3 is expressed at the right time and place to play a role in neural crest development

During early gastrula stages, Xenopus Id3 is expressed in the non-neural ectoderm and subsequently down-regulated in the newly formed neural plate (Fig. 1). Interestingly, expression is maintained at the neural plate border including the prospective neural crest domain. The onset
Figure 6. Id 3 overexpression expands the neural crest precursor domain. (A) Xenopus Id3 (panels $a, b$ ) and Id4 (panel $c$ ) ectopic expression (Red-Gal) expands the neural crest domain as shown by slug expression (purple). Chick Id2 (panel $d$ ), Id3 (panel e), and $I d 4$ (panel $f$ ) also have similar activity. $(B)$ The sections of cranial (panel $a$ ) and trunk (panel $b$ ) neural plates of the stage 14 embryos subjected to BrdUlabeling assay show that the number of proliferating cells (BrdU-labeled cells, brown) is increased upon overexpressing Id3 (X-Gal, turquoise color). (Arrow) Id3-injected side; (arrowhead) control side. (C) The number of pigment cells expressing trp-2 (purple) is increased at the side injected with Id3 RNA (panels $a, c$; Red-Gal), compared with the control side (panels $b, d)$ at stage 33 .
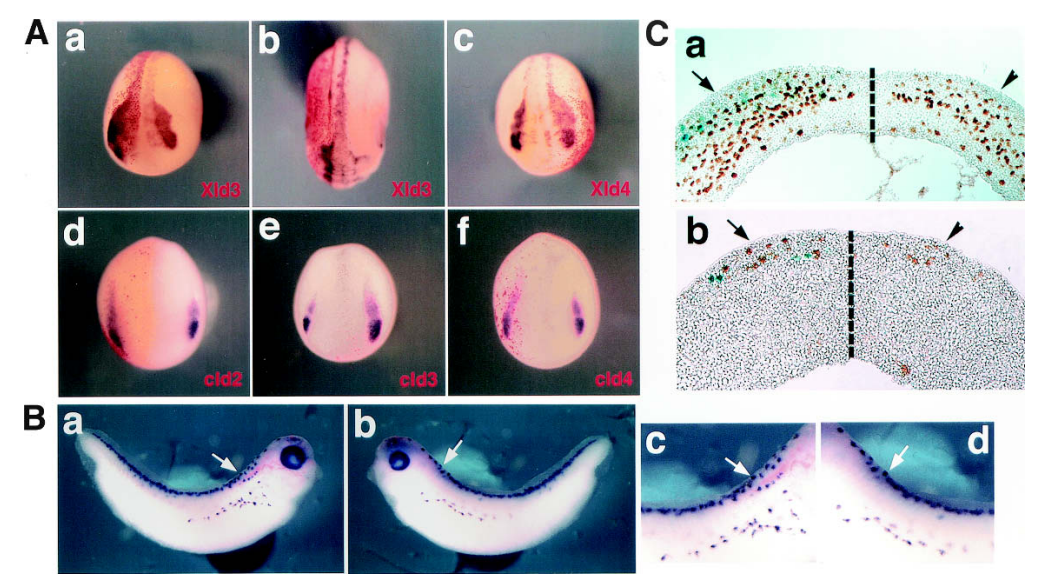
of Id3 expression significantly precedes that of genes known to affect neural crest cell specification, such as c-myc or slug, which are expressed at midgastrula stages onward. Thus, Id3 may promote proliferation before these cells are specified toward a neural crest fate. Alternatively, it may promote continuous proliferation of neural crest progenitors until they differentiate at appropriate target sites.

The regulation of early Id3 expression through gastrula to early neurula stages correlates with molecular patterning events involved in early neural and neural crest induction. It has been shown that neural crest induction in Xenopus involves a combination of signals, including BMP antagonists secreted by the organizer and a second signal mimicked by Wnt or FGF from the prospective epidermis or mesoderm. Consistent with this, we find that $I d 3$ expression is down-regulated in animal cap assays in the presence of a BMP antagonist or Wnt alone but maintained or up-regulated (depending on the half-life of the $I d 3$ gene) under neural crest-inducing conditions when Wnt is combined with Chordin (Fig. 2). This suggests that Id 3 expression may be regulated by the same signals that influence the onset of expression of neural crest markers like slug and soxE genes.

\section{Id3 is an essential early regulator of neural crest formation}

The results from morpholino oligonucleotide-mediated depletion of Id3 protein show that Id3 is necessary for the expression of early neural crest markers such as slug, sox10, and foxD3 (Fig. 3C) as well as for development of cranial and trunk neural crest derivatives at tadpole stages (Fig. 4). Furthermore, Id3 is essential for neural crest cell proliferation and survival, accounting for the defects in neural crest development in Id3-depleted embryos (Fig. 5). The reduced or ablated cartilages observed in the branchial arches of Id3-depleted embryos appear to be a consequence of early disruption of the neural crest progenitor pool.

Neural crest precursors are mitotic cells from their formation through migration. Some migrating neural crest cells become post-mitotic and undergo differentiation much later, for example, when they differentiate into peripheral ganglia (Kahane and Kalcheim 1998). The finding that proliferation was blocked in Id3-depleted embryos (Fig. 5B,C) suggests that this gene is required for maintaining neural crest progenitors in a mitotic state. In addition to the neural folds, the anterior neural plate expresses Id 3 and represents a domain containing placode precursors, suggesting a similar role for Id3 in proliferation of both placodal and neural crest cells.

Under normal conditions, TUNEL staining is low or absent during gastrulation and neurulation, probably due to the rapid degradation of apoptotic cells with a turnover time of $1 \mathrm{~h}$ or less (Jacobson et al. 1997; Hensey and Gautier 1998; Yeo and Gautier 2003). Cell cycle inhibition slows down the rate at which dying cells are degraded, thus allowing more cells to be detected by TUNEL at a given time (Yeo and Gautier 2003). Id3- depleted embryos clearly showed increased TUNELpositive staining on the injected side, possibly due to a blockade of the cell cycle and subsequent cell death. The larger size of TUNEL-positive cells in Id3-depleted embryos suggests that mitosis may be blocked. Morpholino oligonucleotide-based depletion of Id3 protein resulted in ectopic expression of cell cycle inhibitor $\mathrm{p} 27^{\mathrm{XicI}}$ and progressive cell death starting from late-gastrula through neurula stages. These results suggest that Id 3 activity in neural crest progenitors is likely coupled to the cell cycle. From this perspective, the expression of Id 3 at the neural plate border makes sense, since border cell types such as neural crest progenitors must remain multipotent and unresponsive to signals that may influence neighboring cells to form epidermis or central nervous system.

The results from our experiments suggest a molecular model of how Id 3 works in neural crest progenitors at early development (Fig. 7). Id3 may bind a transcription factor that is required for activating the expression of cell cycle inhibitors and, thus, inhibit DNA binding of the transcription factor by sequestering it and preventing formation of homo- or heterodimers. As a consequence, the expression of cell cycle inhibitor may be repressed, facilitating cell cycle progression and survival. Id3 depletion, however, may allow the transcription factor to form dimers that bind to DNA and activate the expression of cell cycle inhibitors that block the cell cycle, followed by cell death of the neural crest population.

The present results suggest that Id 3 is one of the few "neural crest" genes that play a critical role in cell cycle progression and survival at early stages of neural crest development. All other neural crest genes identified in Xenopus to date have been shown to be involved in cell fate specification, although Sox10 has been suggested to be important in both neural crest cell specification and survival (Honore et al. 2003). What factors control cell proliferation and survival of neural crest and how are they related to regulators of cell fate determination and differentiation? FoxD3 is specifically expressed in neural crest precursors and undifferentiated embryonic stem cells (Sutton et al. 1996) and is required for embryonic

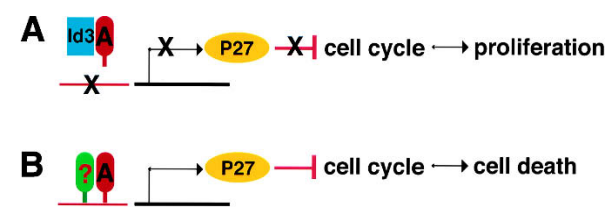

Figure 7. Molecular function of Id 3 in neural crest progenitors: proliferation or death. $(A) \operatorname{Id} 3$ binds the " $\mathrm{A}$ " transcription factor that is required for activating the expression of cell cycle inhibitors such as $\mathrm{p} 27^{\mathrm{Xic1}}$ and inhibits DNA binding of the A-factor by sequestering it from making homo- or heterodimers. This represses the expression of cell cycle inhibitor and facilitates cell cycle progression and survival. $(B) \mathrm{Id} 3$ depletion allows the A transcription factor to make dimers that can bind DNA and activate the expression of the cell cycle inhibitor. The cell cycle inhibitor blocks the cell cycle, followed by cell death of neural crest progenitors. 
stem cell establishment and maintenance (Hanna et al. 2002). Sox10 is another transcription factor that inhibits differentiation and maintains stem cell potential (Kim et al. 2003). In addition, Id genes are known to affect proliferation of neuroepithelial cells and undifferentiated brain regions during central nervous system development (Evans and O'Brien 1993; Ellmeier and Weith 1995; Jen et al. 1997). Id2 has been shown to enhance cell proliferation and interact with the retinoblastoma $(\mathrm{Rb})$ proteins, mediating cell cycle progression by Myc (Iavarone et al. 1994; Lasorella et al. 1996, 2000; Toma et al. 2000; Yokota and Mori 2002). Taken together, these results suggest that transcriptional regulators such as $\operatorname{Id} 3$, Sox10, and FoxD3, which are expressed in neural crest progenitors, may function in parallel pathways during neural crest development, either establishing and/or maintaining the neural crest stem cell potential at early stages. The progressive down-regulation of the Id gene expression during neural induction suggests that Id genes may regulate the cell cycle and define proliferative zones in specific cell populations.

While the present work clearly shows that $\mathrm{Id} 3$ is required for neural crest cell proliferation and survival, it is also likely that $\mathrm{Id} 3$ regulates the formation of other cell types that originate from the neural plate border and placodal domain. Both early and later expression of Sox10 in the neural crest was lost (Figs. 3C, 5F), and n-tubulin-expressing cranial ganglia cells were also affected in Id3-depleted embryos (data not shown), suggesting that the neurogenic placodes fail to form in these embryos.

\section{The function of Id genes may be conserved in neural crest development}

An interesting paradox is why single or double knockouts of Id genes in mice have no obvious defect in the neural crest, whereas Xenopus Id3 depletion alone results in neural crest defects. Id1, Id2, and Id 3 are all expressed in the neural fold in mice (Evans and O'Brien 1993; Jen et al. 1997; Andres-Barquin et al. 2000). In chick, Id2 is expressed in premigratory and migratory cranial neural crest cells and Id4 later in cranial dorsal neural tubes and in small subsets of migrating neural crest cells, as well as Id1 in neural crest cells around eyes in 3-d embryos (Martinsen and Bronner-Fraser 1998; Kee and Bronner-Fraser 2001a,b). In Xenopus, however, only Id 3 among known Id genes (Id1 has not been reported yet) is expressed in neural crest progenitors during a critical period for early neural crest induction. On the other hand, overexpression of any of the Id genes in Xenopus expands the expression domain of early neural crest markers without interrupting neural crest specification (Fig. 6). The unique role of Id3 is due to the fact that it is the sole Id gene deployed in the neural crest rather than due to functional differences among different paralogs. In mouse, on the other hand, the functional redundancy of Id genes and their coexpression in premigratory neural crest may explain the absence of a neural crest phenotype in Id mutant mice.
Similar to our results in Xenopus, overexpression of Id 2 in chick results in expansion of the number of neural crest cells (Martinsen and Bronner-Fraser 1998). Rather than influencing neural crest specification, however, the present results make it clear that Ids have an earlier effect on proliferation/apoptosis that could not be gleaned from a gain-of-function approach in chick. Thus, the present findings reveal a previously unknown role for Id genes in neural crest development.

\section{Concluding remarks}

Recent molecular studies have identified molecules that regulate neural crest development from the embryonic ectoderm, nearly all of which function in cell fate determination. By taking advantage of the ease of performing molecular embryological manipulations in Xenopus such as focal injection of $\operatorname{Id} 3$ antisense oligos and the ability to target the prospective neural crest, we explored the function of the transcriptional regulator Id3. Our results show that Id3 is essential for cell cycle progression and survival of neural crest progenitors during early embryogenesis in Xenopus, rather than having a role in cell fate decisions. Furthermore, Id3 among the known Id genes is the only one that is expressed in the Xenopus premigratory neural crest, thus allowing us to specifically examine the effects of Id3 depletion. In contrast, Id-null mice show no obvious phenotype in neural crest development, probably because of the overlapping expression patterns and redundant functions of different Id genes in the mouse neural folds. In proliferating and nonterminally differentiated neural crest progenitors, Id3 may function to prevent premature differentiation or cell fate determination until these cells migrate and arrive at their correct locations. Our study highlights a unique role for cell proliferation and survival in neural crest development and defines a key molecular regulator of these events.

\section{Materials and methods}

\section{Embryo manipulation and in situ hybridization}

Xenopus embryos were obtained by in vitro fertilization from pigmented and albino females and testis from pigmented males and grown in $0.1 \times$ MMR by standard methods (Sive et al. 2000) and staged according to Nieuwkoop and Faber (1994). The vitelline membrane was removed at the appropriate stages, and embryos were fixed in MEMFA for $1 \mathrm{~h}$, washed three times in PBS with $1 \mathrm{mM} \mathrm{MgCl}_{2}$ for $5 \mathrm{~min}$ each, and processed for $\beta$-galactosidase activity in staining solution [PBS at $\mathrm{pH} 7.4,10 \mathrm{mM}$ $\left.\mathrm{K}_{3} \mathrm{Fe}(\mathrm{CN})_{6}, 10 \mathrm{mM} \mathrm{K}_{4} \mathrm{Fe}(\mathrm{CN})_{6}, 2 \mathrm{mM} \mathrm{MgCl}_{2}\right]$ with 5-bromo-4chloro-3-indolyl- $\beta$-D-galactoside (X-Gal; Invitrogen) for turquoise color or 6-chloro-3-indolyl-b-D-galactoside (Red-Gal; Research Organics) for red color. The embryos were washed in PBS, dehydrated in ethanol, and stored at $-20^{\circ} \mathrm{C}$.

Whole-mount in situ hybridization on embryos was performed as described by Harland (1991). Embryos were developed with BM purple (Roche) for purple color or 5-bromo-4-chloro-3indolyl-phopshate (BCIP; Invitrogen) for light blue, in the presence of $1 \mathrm{mM}$ Tetramisole (Sigma). After color development, 
wild-type embryos were fixed in MEMFA for $1 \mathrm{~h}$, washed in PBS, and bleached in $0.5 \times$ SSC, $5 \%$ formamide, and $1 \%$ hydrogen peroxide under fluorescent light. Stained embryos were embedded in gelatin and sectioned at 10-30 $\mu \mathrm{M}$.

\section{Animal cap assay and RT-PCR}

Embryos were injected with 100 pg of chordin RNA and/or 200 pg of wnt8 RNA at the two-cell stage for neural crest induction in naïve ectoderm. Animal caps were dissected at stage 9, cultured in $75 \%$ NAM until sibling control embryos reached stage 18 , and then harvested for RT-PCR. RNA was extracted from whole embryos or animal caps by proteinase $\mathrm{K}$ treatment (ICN Pharmaceuticals; $250 \mu \mathrm{g} / \mathrm{mL}$ in $20 \mathrm{mM}$ Tris at $\mathrm{pH} 8.0,100 \mathrm{mM}$ $\mathrm{NaCl}, 30 \mathrm{mM}$ EDTA, $1 \% \mathrm{SDS}$ ) for $1 \mathrm{~h}$ at $37^{\circ} \mathrm{C}$. DNA was removed by RNase-free DNase I (Roche). cDNA was synthesized using Superscript II Reverse Transcriptase (Invitrogen) with random hexamers according to the manufacturer's instructions. The amount of cDNA used in RT-PCR was normalized for EF1 $\alpha$. RT-PCR for Xenopus Id genes (Liu and Harland 2003) and slug (LaBonne and Bronner-Fraser 1998) was performed using PCR conditions and primers as described.

\section{DNA constructs and RNA synthesis}

Xenopus Id2, Id3, and Id4 genes in cs107 vectors were gifts of K. Liu and R. Harland (University of Californialey, Berkeley, CA) (Liu and Harland 2003). The open reading frames of chick Id1, Id2, Id3, and Id4 genes (Martinsen and Bronner-Fraser 1998; Kee and Bronner-Fraser 2001a,b,c) were cloned into a pCS2+ vector by PCR using EcoRI sites, and the nucleotide sequence of each clone was confirmed by sequencing to prevent mutation at the amino acid level.

Synthetic capped RNA was generated using the mMessage mMachine kit (Ambion). Xenopus Id2, Id3, and Id4 in cs107 (AscI, SP6); chick Id1 (KpnI, SP6), Id2 (NotI, SP6), Id3 (NotI, SP6), Id3-nls (NotI, SP6), and Id4 (NotI, SP6) in pCS2+; wnt8SP64T (EcoRI, SP6, from R.T. Moon, University of Washington School of Medicine, Seattle, WA); chordin (NotI, SP6, from E.M. DeRobertis, University of California at Los Angeles, Los Angeles, CA); EGFP-pCS2+ (ApaI, SP6, from R. Davis, Harvard Medical School, Cambridge, MA).

The RNA probes for in situ hybridization were synthesized as listed: Xenopus foxD3 (EcoRI, T7, from Y. Sasai, Center for Developmental Biology, Minatojima-minamimachi, Chuo Kobe, Japan); Id3 (cs107 Id3-codL, HindIII, T7, from R. Harland); $n$ - $\beta$ gal (NotI, SP6, from D. Turner, Harard Medical School, Boston, MA); n-tubulin (BamHI, T3, from C. Kintner, The Salk Institute for Biological Studies, La Jolla, CA); p27 ${ }^{\text {Xic1 }}$ (BamHI, T7, from N. Papalopulu, Cambridge Institute for Medical Research, Cambridge, UK); slug (BglII, SP6, from R. Mayor, Universidad de Chilé, Santiago, Chilé); sox2 (XbaI, T7, from R. Grainger, University of Virginia, Charlottesville, VA); trp-2 (pGEMT-Xtrp-2, NcoI, SP6, from J.P. Saint-Jeannet, University of Pennsylvania, Philadelphia, PA).

\section{Morpholino experiments}

The antisense morpholino oligonucleotide was designed to target a region of Xenopus Id3, ending at 8 bp upstream of the translation-initiation site (Id3-MO, 5'-GGGTGTCAGAGATG ATTGCTGGAGC-3'). Controls included an oligonucleotide containing seven mismatches in the Id3-MO sequence (controlMO, 5'-GGTTGTTAGACATCATTACTAGAAC-3') and the morpholino oligonucleotide sequence against Xenopus Id2 (Id2-MO, 5'-AGCTTTCATAGTACCGCTTAGATAT-3'). These oligos (Gene Tools LLC) were tested for their ability to block Id3 protein translation from an Id 3 construct containing the $5^{\prime}$-UTR (cs107 Id3-codL) in in vitro translation assays using rabbit reticulocyte lysate (Promega) and $\left[{ }^{35} \mathrm{~S}\right]$ methionine (Perkin Elmer). Embryos were injected with morpholino oligos into one cell at the eight-cell stage at a dose of 1-10 ng per embryo. Embryos were collected at gastrula or neurula stage and subjected to in situ hybridization, proliferation assay, or TUNEL staining.

\section{Proliferation assay}

Phosphohistone H3 immunohistochemistry was performed to identify mitotic cells. Embryos injected with morpholino oligos were processed as mentioned above and kept in ethanol at $-20^{\circ} \mathrm{C}$ until the proliferation assay was performed. Embryos were rehydrated to PBS, washed in PBT $(1 \times \mathrm{PBS}$ at $\mathrm{pH} 7.2,0.2 \%$ BSA, $0.1 \%$ Triton X-100), and blocked in PBT $/ 10 \%$ heat-treated goat serum. Anti-phosphohistone H3 antibody (Upstate Biotechnology) was used at a dilution of 1:250 in $\mathrm{PBT} / 5 \%$ heattreated goat serum at $4{ }^{\circ} \mathrm{C}$ overnight followed by anti-rabbit IgG conjugated with horse radish peroxidase (Zymed) at 1:500. Black dots indicating cells in mitosis were developed with 3,3'-diaminobenzidine, cobalt/nickel chloride, and hydrogen peroxide.

BrdU labeling was performed as previously described (Hardcastle and Papalopulu 2000). The embryos injected with Id3 RNA at four- to eight-cell stages were grown until mid- to late gastrula, injected with BrdU, collected in an hour, and then subjected to immunohistochemistry, according to the methods of Dr. N. Papalopulu (Hardcastle and Papalopulu 2000).

\section{TUNEL staining}

TUNEL assays were performed as previously described (Hensey and Gautier 1998). The embryos injected with morpholino oligos were rehydrated in PBS, permeablized in PBS containing $0.5 \%$ Tween 20 , and washed in TdT (terminal deoxynucletidyl transferase) buffer (Invitrogen). End labeling was carried out in TdT buffer containing $2 \mu \mathrm{M}$ digoxigenin-11-dUTP (Roche) and $150 \mathrm{U} / \mathrm{mL}$ TdT (Invitrogen) at room temperature overnight. Embryos were heat-treated at $65^{\circ} \mathrm{C}$ in PBS/1 mM EDTA for $1 \mathrm{~h}$ to inactivate the enzyme activity, washed in PBS and then in PBT, blocked in $\mathrm{PBT} / 20 \%$ heat-treated goat serum, and incubated with anti-digoxigenin antibody conjugated with alkaline phosphatase (Roche), at a dilution of 1:1000 in PBT/5\% goat serum at $4^{\circ} \mathrm{C}$ overnight. Embryos were washed in PBT and then, in alkaline phosphate buffer, followed by color development in BM purple in the presence of $1 \mathrm{mM}$ Tetramisole. Embryos were scored as TUNEL-positive when the MO-injected side showed significantly more TUNEL staining than the contralateral uninjected side.

\section{Embedding and sectioning in gelatin}

Embryos were equilibrated in $15 \%$ sucrose/PBS, then in $5 \%$ followed by $20 \%$ gelatin/PBS and embedded in $20 \%$ gelatin/ PBS. Frozen blocks were sectioned on Microm cryostat at 10-30 $\mu \mathrm{M}$, and the sections on the slides were dried overnight. Gelatin was removed from slides by incubating in warm gelatin glue $\left(0.6 \%\right.$ gelatin and $80 \%$ ethanol in water) at $37^{\circ} \mathrm{C}$ for $1 \mathrm{~min}$ and washing in water for $3 \mathrm{~min}$, and the slides were then mounted with DPX Mountant for histology (Fluka).

\section{Cartilage staining}

Embryos were fixed in MEMFA at stage 45, dehydrated with ethanol, stained overnight in $0.2 \%$ alcian blue $/ 30 \%$ acetic acid 
in ethanol, and washed through a glycerol series into $80 \%$ glycerol $/ 2 \%$ potassium hydroxide. The stained cartilages were manually dissected to remove adherent tissue.

\section{Acknowledgments}

We especially thank Drs. Scott Fraser, Laura Gammill, Tatjana Sauka-Spengler, Tanya Moreno, Daniel Meulemans, Peter Lwigale, and Byung Joon Hwang for critical comments on this manuscript; Samuel Ki for technical assistance; and members of our laboratories for technical advice and help. We are grateful to the people who provided plasmids, as mentioned in Materials and Methods. This work was supported by an American Heart Association Post-doctoral Fellowship to Y.K. and by NIH grant DE13223 to M.B.-F.

\section{References}

Andres-Barquin, P.J., Hernandez, M.C., and Israel, M.A. 2000. Id genes in nervous system development. Histol. Histopathol. 15: 603-618.

Aoki, Y., Saint-Germain, N., Gyda, M., Magner-Fink, E., Lee, Y.H., Credidio, C., and Saint-Jeannet, J.P. 2003. Sox10 regulates the development of neural crest-derived melanocytes in Xenopus. Dev. Biol. 259: 19-33.

Baker, C.V. and Bronner-Fraser, M. 2001. Vertebrate cranial placodes I. Embryonic induction. Dev. Biol. 232: 1-61.

Bellmeyer, A., Krase, J., Lindgren, J., and LaBonne, C. 2003. The protooncogene c-myc is an essential regulator of neural crest formation in Xenopus. Dev. Cell 4: 827-839.

Britsch, S., Goerich, D.E., Riethmacher, D., Peirano, R.I., Rossner, M., Nave, K.A., Birchmeier, C., and Wegner, M. 2001. The transcription factor Sox10 is a key regulator of peripheral glial development. Genes \& Dev. 15: 66-78.

Ellis, H.M., Spann, D.R., and Posakony, J.W. 1990. extramacrochaetae, a negative regulator of sensory organ development in Drosophila, defines a new class of helix-loop-helix proteins. Cell 61: 27-38.

Ellmeier, W. and Weith, A. 1995. Expression of the helix-loophelix gene Id3 during murine embryonic development. Dev. Dyn. 203: 163-173.

Essex, L.J., Mayor, R., and Sargent, M.G. 1993. Expression of Xenopus snail in mesoderm and prospective neural fold ectoderm. Dev. Dyn. 198: 108-122.

Evans, S.M. and O'Brien, T.X. 1993. Expression of the helixloop-helix factor Id during mouse embryonic development. Dev. Biol. 159: 485-499.

Gammill, L.S. and Bronner-Fraser, M. 2003. Neural crest specification: Migrating into genomics. Nat. Rev. Neurosci. 4: 795-805.

Garrell, J. and Modolell, J. 1990. The Drosophila extramacrochaetae locus, an antagonist of proneural genes that, like these genes, encodes a helix-loop-helix protein. Cell 61: 3948.

Groves, A.K. and Bronner-Fraser, M. 1999. Neural crest diversification. Curr. Top. Dev. Biol. 43: 221-258.

Hanna, L.A., Foreman, R.K., Tarasenko, I.A., Kessler, D.S., and Labosky, P.A. 2002. Requirement for Foxd3 in maintaining pluripotent cells of the early mouse embryo. Genes \& Dev. 16: $2650-2661$.

Hardcastle, Z. and Papalopulu, N. 2000. Distinct effects of $\mathrm{XBF}-1$ in regulating the cell cycle inhibitor p27(XIC1) and imparting a neural fate. Development 127: 1303-1314.

Harland, RM. 1991. In situ hybridization: an improved whole- mount method for Xenopus embryos. Methods Cell. Biol. 36: 685-695

Hensey, C. and Gautier, J. 1998. Programmed cell death during Xenopus development: A spatio-temporal analysis. Dev. Biol. 203: 36-48.

Honore, S.M., Aybar, M.J., and Mayor, R. 2003. Sox10 is required for the early development of the prospective neural crest in Xenopus embryos. Dev. Biol. 260: 79-96.

Iavarone, A., Garg, P., Lasorella, A., Hsu, J., and Israel, M.A. 1994. The helix-loop-helix protein Id-2 enhances cell proliferation and binds to the retinoblastoma protein. Genes \& Dev. 8: 1270-1284.

Jacobson, M.D., Weil, M., and Raff, M.C. 1997. Programmed cell death in animal development. Cell 88: 347-354.

Jen, Y., Manova, K., and Benezra, R. 1997. Each member of the Id gene family exhibits a unique expression pattern in mouse gastrulation and neurogenesis. Dev. Dyn. 208: 92-106.

Kahane, N. and Kalcheim, C. 1998. Identification of early postmitotic cells in distinct embryonic sites and their possible roles in morphogenesis. Cell Tissue Res. 294: 297-307.

Kee, Y. and Bronner-Fraser, M. 2001a. Id4 expression and its relationship to other Id genes during avian embryonic development. Mech. Dev. 109: 341-345.

-2001b. Temporally and spatially restricted expression of the helix-loop-helix transcriptional regulator Id1 during avian embryogenesis. Mech. Dev. 109: 331-335.

- 2001c. The transcriptional regulator Id 3 is expressed in cranial sensory placodes during early avian embryonic development. Mech. Dev. 109: 337-340.

Kim, J., Lo, L., Dormand, E., and Anderson, D.J. 2003. SOX10 maintains multipotency and inhibits neuronal differentiation of neural crest stem cells. Neuron 38: 17-31.

Knecht, A.K. and Bronner-Fraser, M. 2002. Induction of the neural crest: A multigene process. Nat. Rev. Genet. 3: 453-461.

LaBonne, C. and Bronner-Fraser, M. 1998. Neural crest induction in Xenopus: Evidence for a two-signal model. Development 125: 2403-2414.

- 1999. Molecular mechanisms of neural crest formation. Annu. Rev. Cell Dev. Biol. 15: 81-112.

- 2000. Snail-related transcriptional repressors are required in Xenopus for both the induction of the neural crest and its subsequent migration. Dev. Biol. 221: 195-205.

Lasorella, A., Iavarone, A., and Israel, M.A. 1996. Id2 specifically alters regulation of the cell cycle by tumor suppressor proteins. Mol. Cell. Biol. 16: 2570-2578.

Lasorella, A., Noseda, M., Beyna, M., Yokota, Y., and Iavarone, A. 2000. Id2 is a retinoblastoma protein target and mediates signalling by Myc oncoproteins. Nature 407: 592-598.

Le Douarin, N. and Kalcheim, C. 1999. The neural crest. Cambridge University Press, Cambridge, UK.

Liu, K.J. and Harland, R.M. 2003. Cloning and characterization of Xenopus Id4 reveals differing roles for Id genes. Dev. Biol. 264: 339-351.

Luo, T., Lee, Y.H., Saint-Jeannet, J.P., and Sargent, T.D. 2003. Induction of neural crest in Xenopus by transcription factor AP2 $\alpha$. Proc. Nat1. Acad. Sci. 100: 532-537.

Lyden, D., Young, A.Z., Zagzag, D., Yan, W., Gerald, W., O'Reilly, R., Bader, B.L., Hynes, R.O., Zhuang, Y., Manova, K., et al. 1999. Id1 and Id3 are required for neurogenesis, angiogenesis and vascularization of tumour xenografts. $\mathrm{Na}$ ture 401: 670-677.

Marchant, L., Linker, C., Ruiz, P., Guerrero, N., and Mayor, R. 1998. The inductive properties of mesoderm suggest that the neural crest cells are specified by a BMP gradient. Dev. Biol. 198: 319-329.

Martinsen, B.J. and Bronner-Fraser, M. 1998. Neural crest speci- 
fication regulated by the helix-loop-helix repressor Id2. Science 281: 988-991.

Mayor, R., Guerrero, N., and Martinez, C. 1997. Role of FGF and noggin in neural crest induction. Dev. Biol. 189: 1-12.

Mayor, R., Guerrero, N., Young, R.M., Gomez-Skarmeta, J.L., and Cuellar, C. 2000. A novel function for the Xslug gene: Control of dorsal mesendoderm development by repressing BMP-4. Mech. Dev. 97: 47-56.

Nieuwkoop, P.D. and Faber, J. 1994. Normal table of Xenopus laevis (Daudin): A systematical and chronological survey of the development from the fertilized egg till the end of metamorphosis. Garland, New York.

Norton, J.D. 2000. ID helix-loop-helix proteins in cell growth, differentiation and tumorigenesis. J. Cell Sci. 113 (Pt 22): 3897-3905.

Norton, J.D., Deed, R.W., Craggs, G., and Sablitzky, F. 1998. Id helix-loop-helix proteins in cell growth and differentiation. Trends Cell Biol. 8: 58-65.

Saint-Jeannet, J.P., He, X., Varmus, H.E., and Dawid, I.B. 1997. Regulation of dorsal fate in the neuraxis by Wnt-1 and Wnt3a. Proc. Nat1. Acad. Sci. 94: 13713-13718.

Sasai, N., Mizuseki, K., and Sasai, Y. 2001. Requirement of FoxD3-class signaling for neural crest determination in Xenopus. Development 128: 2525-2536.

Sherr, C.J. and Roberts, J.M. 1999. CDK inhibitors: Positive and negative regulators of G1-phase progression. Genes \& Dev. 13: $1501-1512$.

Sive, H.L., Grainger, R.M., and Harland, R.M. 2000. Early development of Xenopus laevis: A laboratory manual. Cold Spring Harbor Laboratory Press, Cold Spring Harbor, NY.

Spokony, R.F., Aoki, Y., Saint-Germain, N., Magner-Fink, E., and Saint-Jeannet, J.P. 2002. The transcription factor Sox9 is required for cranial neural crest development in Xenopus. Development 129: 421-432.

$\mathrm{Su}$, J.Y., Rempel, R.E., Erikson, E., and Maller, J.L. 1995. Cloning and characterization of the Xenopus cyclin-dependent kinase inhibitor p27XIC1. Proc. Natl. Acad. Sci. 92: 1018710191.

Sutton, J., Costa, R., Klug, M., Field, L., Xu, D., Largaespada, D.A., Fletcher, C.F., Jenkins, N.A., Copeland, N.G., Klemsz, M., et al. 1996. Genesis, a winged helix transcriptional repressor with expression restricted to embryonic stem cells. J. Biol. Chem. 271: 23126-23133.

Toma, J.G., El-Bizri, H., Barnabe-Heider, F., Aloyz, R., and Miller, F.D. 2000. Evidence that helix-loop-helix proteins collaborate with retinoblastoma tumor suppressor protein to regulate cortical neurogenesis. J. Neurosci. 20: 7648-7656.

Tribulo, C., Aybar, M.J., Nguyen, V.H., Mullins, M.C., and Mayor, R. 2003. Regulation of Msx genes by a Bmp gradient is essential for neural crest specification. Development 130: 6441-6452.

Tzeng, S.F. 2003. Inhibitors of DNA binding in neural cell proliferation and differentiation. Neurochem. Res. 28: 45-52.

Vidwans, S.J. and Su, T.T. 2001. Cycling through development in Drosophila and other metazoa. Nat. Cell Biol. 3: E35-E39.

Wilson, R. and Mohun, T. 1995. XIdx, a dominant negative regulator of bHLH function in early Xenopus embryos. Mech. Dev. 49: 211-222.

Yeo, W. and Gautier, J. 2003. A role for programmed cell death during early neurogenesis in Xenopus. Dev. Biol. 260: 31-45.

Yokota, Y. 2001. Id and development. Oncogene 20: 8290-8298.

Yokota, Y. and Mori, S. 2002. Role of Id family proteins in growth control. J. Cell Physiol. 190: 21-28.

Zhang, H., Reynaud, S., Kloc, M., Etkin, L.D., and Spohr, G. 1995. Id gene activity during Xenopus embryogenesis. Mech. Dev. 50: 119-130. 


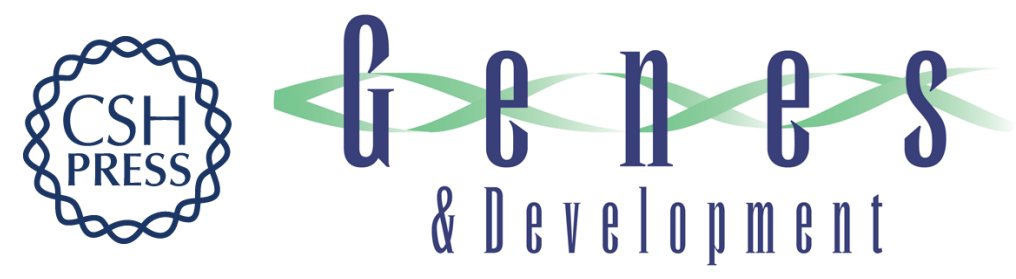

\section{To proliferate or to die: role of Id3 in cell cycle progression and survival of neural crest progenitors}

Yun Kee and Marianne Bronner-Fraser

Genes Dev. 2005, 19:

Access the most recent version at doi:10.1101/gad.1257405

References This article cites 53 articles, 16 of which can be accessed free at: http://genesdev.cshlp.org/content/19/6/744.full.html\#ref-list-1

License

Email Alerting

Receive free email alerts when new articles cite this article - sign up in the box at the top Service right corner of the article or click here.

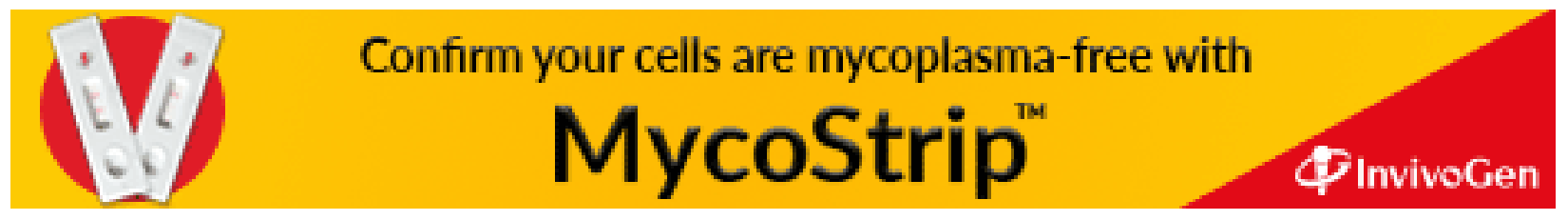

